\title{
Cross-sectional and temporal relationships between bird occupancy and vegetation cover at multiple spatial scales
}

\author{
Ross Cunningham, ${ }^{1}$ David Lindenmayer, ${ }^{1,2,3,4}$ Philip Barton, ${ }^{1}$ Karen Ikin, ${ }^{1}$ Mason Crane, ${ }^{1}$ Damian Michael, ${ }^{1}$ \\ Sachiko OKada, ${ }^{1}$ Philip Gibbons, ${ }^{1}$ and John Stein ${ }^{1}$ \\ ${ }^{1}$ Fenner School of Environment and Society, The Australian National University, Canberra, ACT 0200 Australia \\ ${ }^{2}$ Australian Research Council Centre of Excellence for Environmental Decisions, The Australian National University, Canberra, \\ ACT 0200 Australia \\ ${ }^{3}$ National Environmental Research Program, The Australian National University, Canberra, ACT 0200 Australia
}

Abstract. Scale is a key concept in ecology, but the statistically based quantification of scale effects has often proved difficult. This is exemplified by the challenges of quantifying relationships between biodiversity and vegetation cover at different spatial scales to guide restoration and conservation efforts in agricultural environments. We used data from 2002 to 2010 on 184 sites (viz., site scale) nested within 46 farms (the farm scale), nested within 23 landscapes (the landscape scale). We found cross-sectional relationships with the amount of vegetation cover that were typically positive for woodland birds and negative for open-country birds. However, for some species, relationships differed between spatial scales, suggesting differences in nesting and foraging requirements. There was a $3.5 \%$ increase in the amount of native vegetation cover in our study region between 2002 and 2010, and our analyses revealed that some open country species responded negatively to these temporal changes, typically at the farm and/or site scale, but not the landscape scale. Species generally exhibited stronger cross-sectional relationships with the amount of vegetation cover than relationships between changes in occupancy and temporal changes in vegetation cover. This unexpected result can be attributed to differences in habitat use by birds of existing vegetation cover (typically oldgrowth woodland) vs. plantings and natural regeneration, which are the main contributors to temporal increases in vegetation cover. By taking a multi-scaled empirical approach, we have identified species-specific, scale-dependent responses to vegetation cover. These findings are of considerable practical importance for understanding which species will respond to different scales of protection of existing areas of native vegetation, efforts to increase the amount of native vegetation over time, and both approaches together.

Key words: agricultural environments; southeastern Australia; spatial scale; temporal effects; vegetation cover; woodland birds.

\section{INTRODUCTION}

The vast majority of studies of biodiversity (including those of birds) in agricultural environments have been cross-sectional investigations, with longitudinal studies being relatively uncommon (Likens 1989, Muller et al. 2011). In many agricultural environments over the past 10-20 years, there have been significant changes in the amount of native vegetation cover at multiple spatial scales (Geddes et al. 2011). Positive temporal changes in some agricultural environments are the result of natural regeneration and concerted woodland replanting programs (Munro and Lindenmayer 2011).

The defining characteristic of a longitudinal study is that observations of the same population of units are observed over a period of time, sometimes lasting many

Manuscript received 13 May 2013; revised 5 December 2013; accepted 23 December 2013; final version received 16 January 2014. Corresponding Editor: D. Brunton.

${ }^{4}$ Corresponding author.

E-mail: David.Lindenmayer@anu.edu.au years. These studies are in contrast to simple crosssectional studies, in which outcomes are considered as a single (or average) snapshot in time. The benefit of a longitudinal study is that it is possible to study relationships in changes taking place in a target population. Thus, longitudinal data (Diggle et al. 1996) allow us to distinguish cross-sectional relationships among a population of observational units from temporal relationships from within these units. By virtue of its scope, a longitudinal study is more likely to provide insights into cause-and-effect relationships than a cross-sectional study (Likens 1989).

The concept of spatial scale is central to ecology and refers to the spatial extent of ecological processes and the spatial interpretation of the data (Levin 1992, Chave 2013). Quantifying scale effects can be difficult, and this can limit our understanding of species-habitat relationships. Differences in autecology such as home range, body size, nesting and foraging requirements among different species, suggest that different taxa are likely to respond to the environment at different spatial scales 


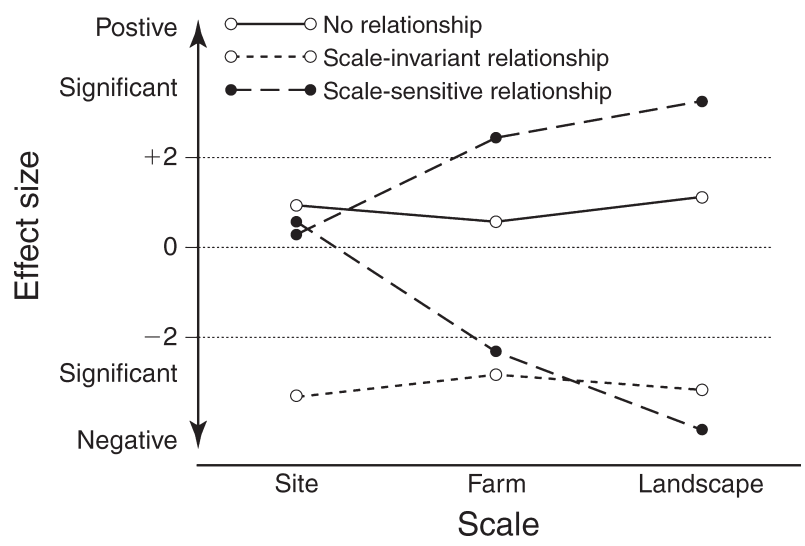

Fig. 1. Potential scenarios showing effect sizes of relationships between occupancy of individual bird species and the amount of native vegetation cover at three different spatial scales.

(Schneider 1994, Carigan and Villard 2002, Chave 2013). Similarly, the same species also may exhibit a particular kind of response to the environment at a specific spatial scale, but might respond differently at a larger or smaller spatial scale (Forman 1964, Diamond 1973, Allen and Hoekstra 1992, Date et al. 1996). For instance, the spatial scale of a suitable nesting site (e.g., within an individual tree hollow) may be different to the spatial scale of foraging or intraspecific competition within a patch. Other key processes may act at yet other scales, such as the regional-level fluctuations in the abundance of a species (Askins et al. 1987), the dispersal of individuals between patches of habitat in a metapopulation (Koenig 1998, Hanski 1999), or the migration of individuals across or between continents (e.g., Guerra and Reppert 2013). To gain insights into such processes, it is important to collect, analyze, and interpret longitudinal data measured at different scales.

In this paper, we statistically examined scale effects on both cross-sectional and temporal relationships through a case study of bird occupancy in the temperate woodlands of southeastern Australia, a region that has been heavily modified by agriculture and livestock grazing (Lindenmayer et al. 2010a). We explored relationships between occupancy by individual species of birds and the amount of native vegetation cover at a snapshot in time as well as changes over time in these variables (i.e., temporal effects). Our data were repeated surveys of birds and vegetation cover from 2002 to 2010 on 184 sites (viz., site scale) nested within 46 farms (farm scale) nested within 23 landscapes (landscape scale). We recognized that for our key response and covariate, we could compute bird occupancy and concomitantly derive the percentage of native vegetation cover at each scale, and so these measures and statistics resulting from our analysis have compatible meaning across different scales. This facilitated, for a selection of individual species of birds, use of our data to examine and compare scale effects under three interrelated research themes: (Theme 1) Cross-sectional relationships. (Theme 2) Temporal relationships. (Theme 3) Contrasts between cross-sectional and temporal relationships. We outline these themes as follows.

\section{Theme 1. Cross-sectional relationships between bird occupancy and the amount of native vegetation cover}

In Theme 1, we estimated cross-sectional relationships between bird occupancy and satellite-derived measures of native vegetation cover at the landscape, farm, and site scales. Spatial scale issues have not been examined in detail in many agricultural landscapes (Tscharntke et al. 2012), and most past cross-sectional work on bird responses to native vegetation cover has been focused at a single scale (e.g., the "landscape scale," as perceived by humans (e.g., $100 \mathrm{~km}^{2}$ [Radford et al. 2005, Maron et al. 2012a]). Several investigations have established strong relationships between the number of species that inhabit a given area and the amount of "habitat" in that area (Andren 1994, Betts et al. 2010, Swift and Hannon 2010, Storch et al. 2012). In addition, several studies have documented relationships between occupancy by an individual species and the amount of "habitat" in a given area (Homan et al. 2004, Radford et al. 2005). We recognized that what constitutes suitable habitat varies between different species (Hall et al. 1997), and for this study, we postulated that woodland-dependent bird species would be more likely to occur on sites, farms, and in landscapes with more native vegetation cover, and conversely, open-country species (i.e., those typically associated with paddocks and cleared pasturelands) would be less likely to occur in such areas.

As part of Theme 1, we also sought to provide empirical support for describing taxa as "scale-sensitive" compared with those that could be classified as "scaleinvariant" (see Fig. 1). We defined scale-sensitive species as those that responded significantly (either positively or negatively) to the amount of native vegetation cover at one or two scales of measurement (for example, at the landscape scale), but nonsignificantly at the other scales (the site and farm scales in this example). We defined scale-invariant species as those that exhibited consistent significant (positive or negative) responses at all three scales of measurement (Fig. 1). We note the important distinction between no response to vegetation cover at any scale and statistical significant response at all or some scales.

\section{Theme 2. Temporal relationships between bird occupancy and the amount of native vegetation cover}

In Theme 2, we explored relationships between temporal changes in bird occupancy and temporal changes in native vegetation cover over the period 2002 to 2010 at each of the three spatial scales. As for Theme 1, we sought to identify scale-sensitive and scaleinvariant species. 


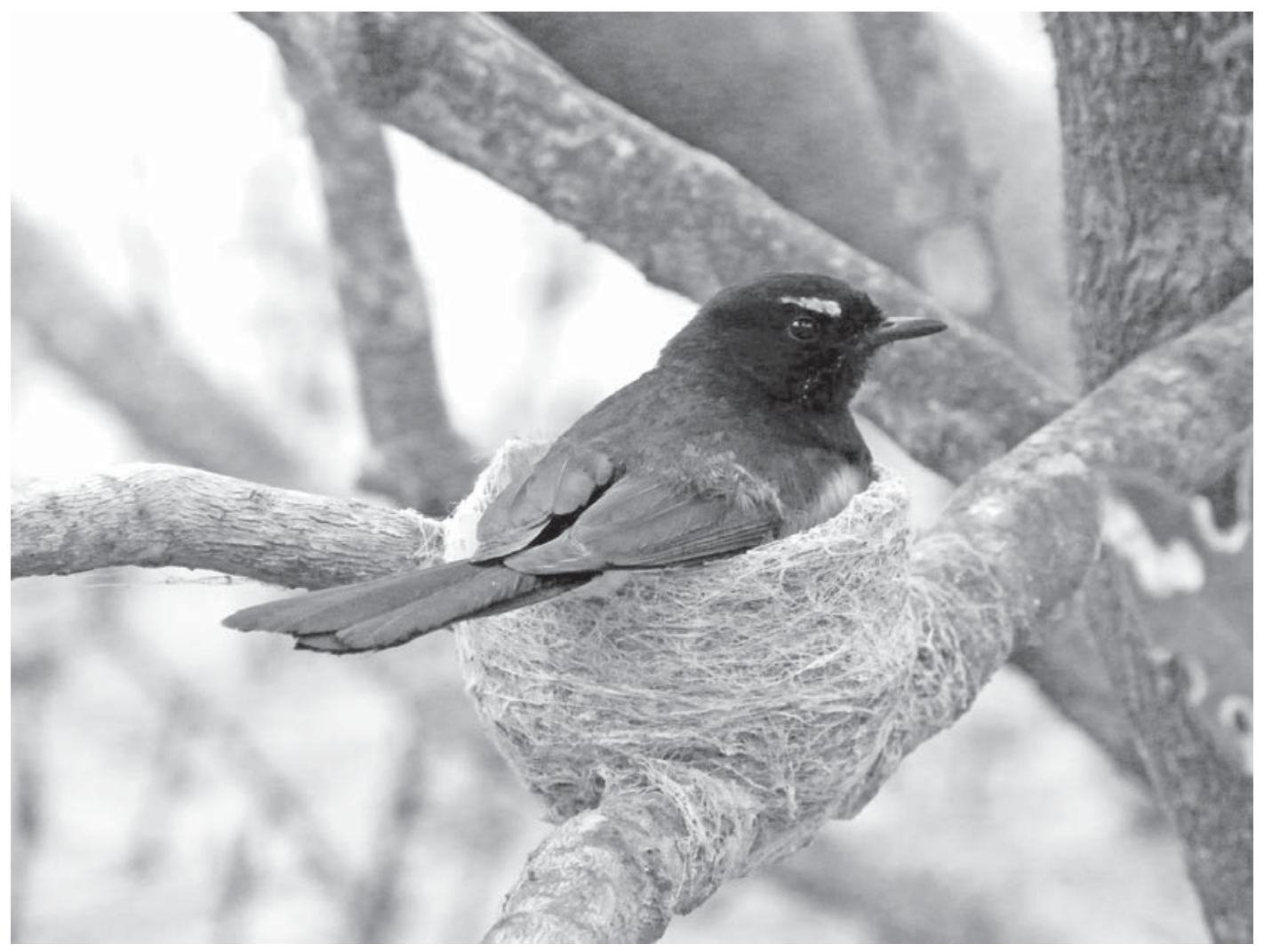

Plate 1. Willie Wagtail on nest. Photo credit: D. Michael.

Theme 3. Comparison of cross-sectional vs. temporal relationships between bird occupancy and amount of native vegetation cover

Finally, for each individual bird species, we compared cross-sectional relationships at different scales with its relationships to temporal changes in vegetation cover at corresponding scales. In environments where active restoration has been taking place, differences between cross-sectional and temporal responses can arise. This may be because vegetation cover at a target spatial unit would be well established (e.g., old-growth woodland), whereas temporal increases in cover would result largely from newly planted areas or natural regeneration. Oldgrowth woodland, natural regeneration, and plantings provide different habitat for birds (Lindenmayer et al. 2012) and hence temporal relationships tell us about direct effects of restoration that may be different from inferences from cross-sectional analyses.

Our aim was to develop a new level of understanding of species-specific scale responses to native vegetation cover in areas dominated by agriculture. However, the effectiveness of conservation efforts in agricultural areas, such as those in agri-environment schemes, are poorly known in most parts of the world (Kleijn et al. 2011). The work we report here will provide an improved understanding of the effectiveness of: (1) protecting (e.g., reserving) existing areas of native vegetation in agricultural areas, and (2) increasing the amount of native vegetation such as through restoration programs, and (3) management interventions at particular spatial scales. Such work also may indicate which species are likely to respond to intervention efforts aimed at increasing native vegetation cover over time.

\section{Methods}

\section{Study area}

Our study was conducted in a $150 \times 120 \mathrm{~km}$ area of the South West Slopes of New South Wales, southeastern Australia, spanning the towns of Junee (0552952 E, $6140128 \mathrm{~N}$ ) in the north and Albury (0494981 E, $6008873 \mathrm{~N}$ ) in the south, and Gundagai (600532 E, $6119073 \mathrm{~N})$ and Howlong (467090 E, 6017897 N) in the east and west, respectively (Fig. 2). Coordinates are UTM. The predominant form of native vegetation was temperate eucalypt woodland (sensu Keith 2004) dominated by White Box, Eucalyptus albens, Grey Box, E. microcarpa, or other eucalypt tree species such as Yellow Box, E. melliodora, Blakely's Red Gum, E. blakelyi, Red Stringybark, E. macrorhyncha, and Red Ironbark, E. sideroxylon. Plantings were areas of planted native vegetation characterized by a mix of local endemic and exotic Australian ground cover, understory and overstory plant species. Most plants 


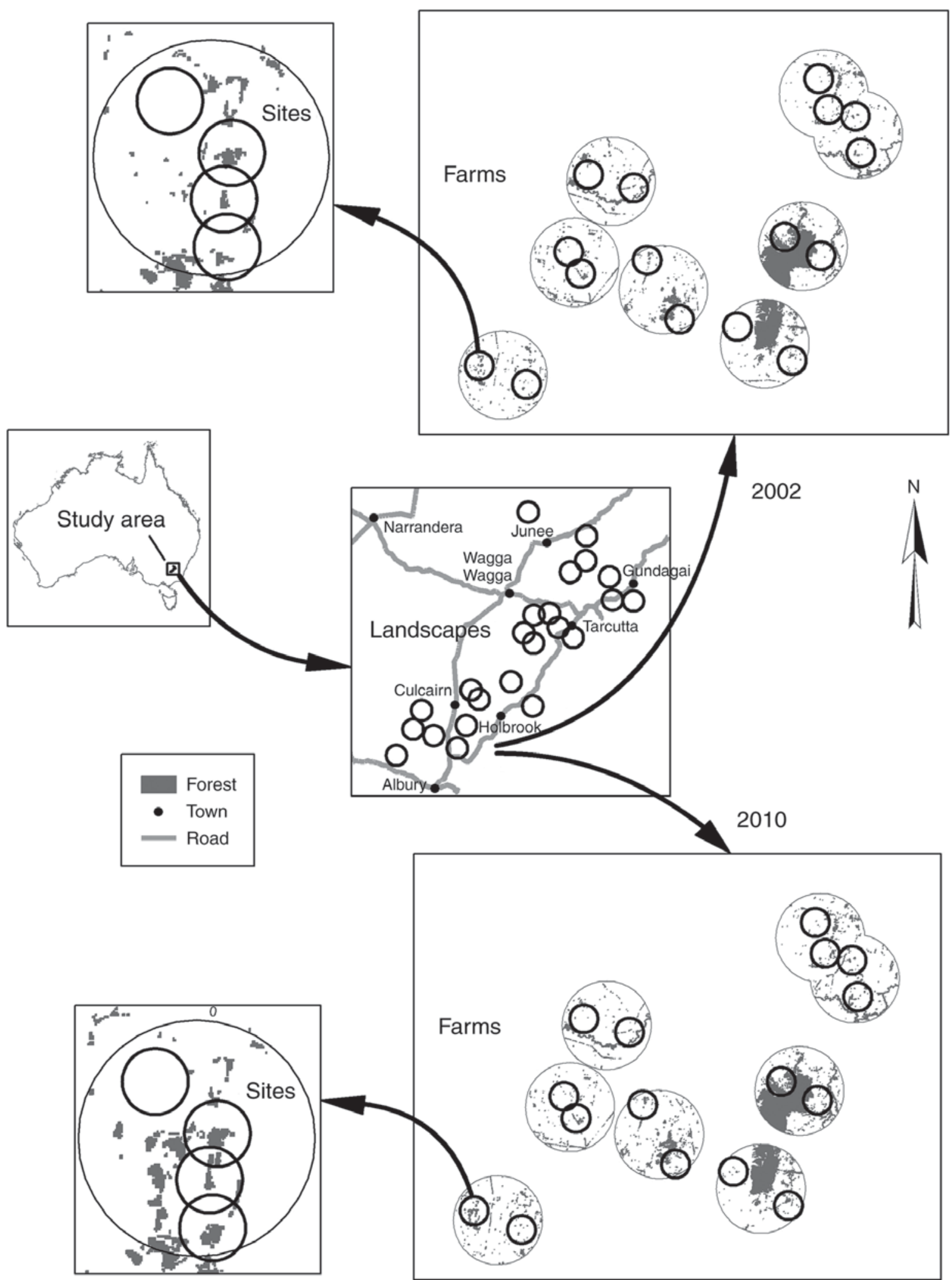

FIG. 2. Map showing 23 landscapes (large circles) each with two farms (medium circles). Within each farm, four 2-ha sites (small circles) were monitored. Shading shows the area of native vegetation cover in years 2002 and 2010. 
a
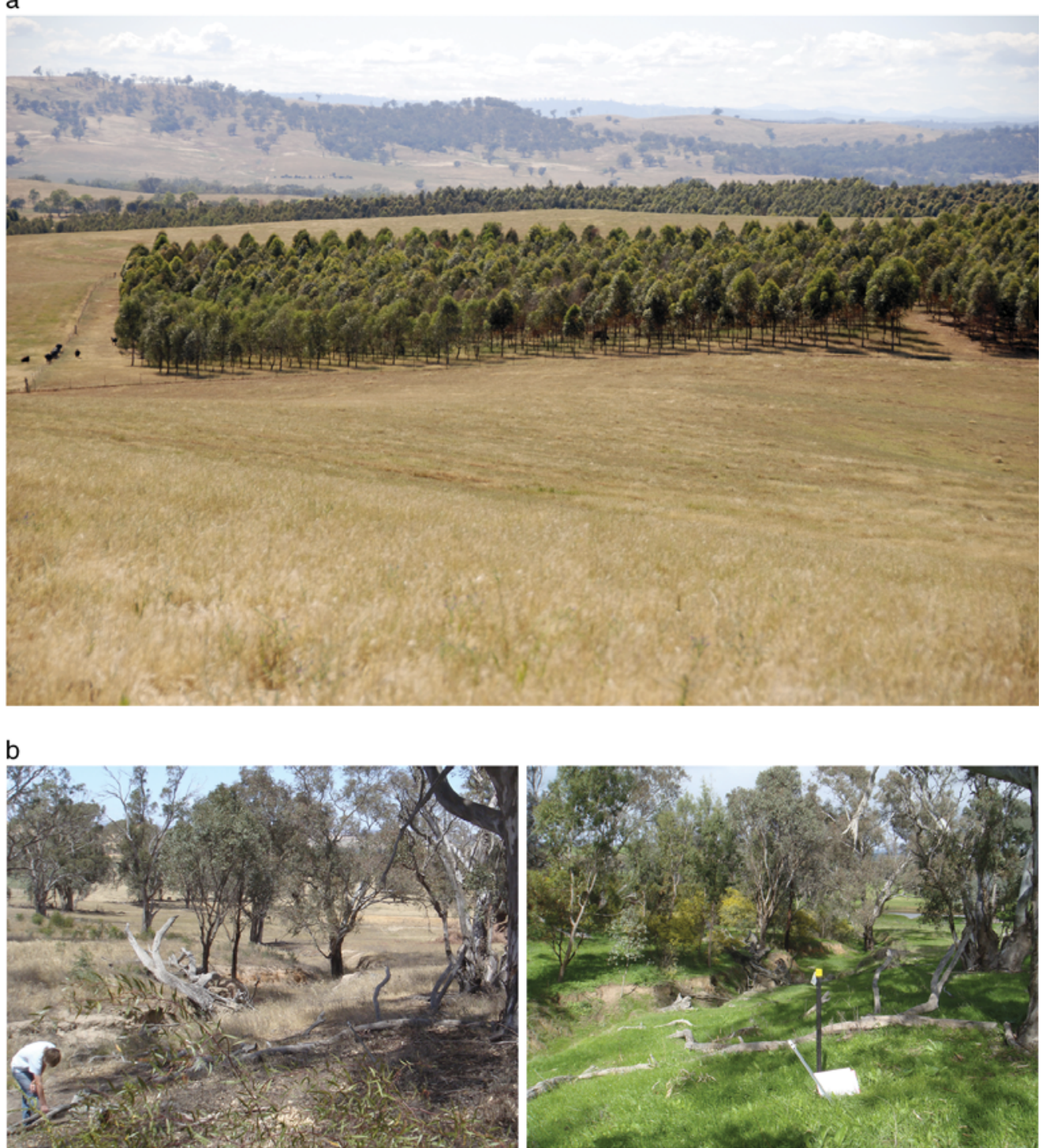

Fig. 3. (a) Extensive plantings on a farm targeted for detailed and repeated field surveys (image taken in mid-2000). (Photo by David Lindenmayer). (b) Photo point showing the extent of vegetation cover in 2002 and 2013. (Photos by Mason Crane and Sachiko Okada).

were typically spaced $2 \mathrm{~m}$ apart, but there was not a standard spacing, and plant species composition protocols applied in revegetation efforts.

The South West Slopes region was ideal for study because: (1) the spatial cover of native vegetation varied from $4 \%$ to $30 \%$ per farm or per landscape; and (2) native vegetation cover on some farms and in some landscapes has been increasing over the past two decades as a result of extensive revegetation programs (Munro and Lindenmayer 2011) and through natural regeneration (Geddes et al. 2011) (e.g., Fig. 3a). These features can be seen on digitized satellite images of our study region (Fig. 2) as well as from photo points taken at the site level (see Fig. 3b as an example).

\section{Study design}

We studied 23 landscapes where a landscape was defined as a relatively homogenous circular area covering $10000 \mathrm{ha}$; these were chosen to represent landscapes with active restoration programs and others without tree planting programs. In "restored" landscapes, one farm ( 1000 ha in size) was selected with plantings and one without. These 46 farms were predominately wheat or canola cropping properties or sheep (Ovis ovis)/cattle (Bos taurus) grazing enterprises. Within each farm, four 2-ha sites were selected, giving a total of 184 sites. On farms with areas of restoration, two sites were plantings and two other sites were remnant vegetation sites. Selection was "pseudo-ran- 
dom" following an informal enumeration of potential landscapes, farms, and sites. Further details on the experimental design are provided in Cunningham et al. (2007).

\section{Bird surveys}

Our study region supports $>170$ bird species (see Appendix A). Over half of these species are woodland dependent. These taxa include $>20$ species of conservation concern (sensu Reid 1999, Montague-Drake et al. 2009). The bird community in the study region includes a range of native "generalist" species that occur in heavily cleared paddocks and cultivated areas (e.g., the Brown Songlark, Cinclorhamphus cruralis). Only four species are exotic, of which the House Sparrow (Passer domesticus) and Common Starling (Sturnus vulgaris) have been declining significantly over the past decade (Lindenmayer and Cunningham 2011).

We completed spring surveys of birds on all 184 sites in 2002, 2004, 2005, 2007, 2008, 2009, and 2010. Our bird-counting protocols entailed repeated five-minute point interval counts (sensu Pyke and Recher 1983) at each of the $0-\mathrm{m}, 100-\mathrm{m}$, and $200-\mathrm{m}$ points along a permanent transect at each site. In each survey year, all sites were surveyed by two different observers on different days. We completed counts within four hours of dawn and did not undertake surveys on days of poor weather (rain, high wind, fog, or heavy cloud cover).

We report results for 24 species at the landscape and farm level, but this was reduced to 19 at the site level, because mean occupancy rates were deemed too low to facilitate meaningful analyses. This suite of species included woodland-associated birds and open-country species, large- and small-bodied birds, and sedentary and wide-ranging species (including summer migrants). Several of these species have been considered to be either declining (e.g., Reid 1999) or at risk of decline (Montague-Drake et al. 2009), including the Brown Treecreeper (Climacteris picumnus), Superb Parrot (Polytelis swainsonii), Rufous Whistler (Pachycephala rufiventris), and Jacky Winter (Microeca fascinans) (see Appendix A). This decline is believed to be, in part, because of a loss of suitable habitat resulting from past vegetation clearing and/or a reduction in vegetation condition as a result of livestock grazing and weed invasion (Ford 2011). The suite of species analyzed also included the Noisy Miner (Manorina melanocephala), which displays aggressive behavior toward other (typically smaller) native species (Clarke and Grey 2010), and hence is considered to be an animal of management concern.

\section{Vegetation cover as a potential explanatory variable}

We considered four measures of vegetation cover: the total (percentage) amount of woody vegetation cover, the number of native vegetation patches, the average patch area (hectares), and the standard deviation of patch area. We calculated each of these measures at the site, farm, and landscape scales using grids of annual forest extent and change between 2002 and 2010 derived from satellite imagery (Furby 2002). Grid resolution was $25 \times 25 \mathrm{~m}$, and vegetation cover was allocated to grid cells where the minimum canopy cover was $20 \%$ over a minimum area of 0.2 ha, with potential height at least $2 \mathrm{~m}$. We calculated measures of woody vegetation for a site by considering all grid cells within $500 \mathrm{~m}$ of the center of a site $(\sim 80 \mathrm{ha})$. We also calculated values for these measures at the farm scale, a $2-\mathrm{km}$ radius around the center of a farm $(\sim 1300 \mathrm{ha})$, and at the landscape scale, a 5.6-km radius ( $\sim 10000 \mathrm{ha})$. We found strong effects for one of the four measures, $\log \%$ of native vegetation cover, with only very limited additional information from analyzing the other three (i.e., number of patches, average patch area, the standard deviation of patch area). Therefore, we presented our findings only for $\log$ of the percentage vegetation cover.

\section{Statistical analysis}

Interpolation of estimates of bird occupancy in 2002 and 2010.-For simplicity, we describe a statistical model for landscape-scale bird occupancy. For each species our principal objective was to obtain a "best" estimate of occupancy at two time points, 2002 and 2010. This was achieved by considering all surveys simultaneously and modeling the trends for each landscape. We briefly describe our statistical approach below.

We fitted a linear logistic model with $\operatorname{logit}(p)$ as the response variable (where $p$ is the occupancy rate), with terms Landscape, Time (as a linear effect) and Landscape $\times$ (linear) Time interaction as fixed effects. This model facilitated prediction of "linearly smoothed" logit(bird occupancy) values at each landscape for each year, together with estimates of the variance of the predicted values. We used "linearly smoothed" predicted bird occupancy values for each landscape at spring 2002 and spring 2010 as data for the next stage of analysis.

Modelling the relationship between bird occupancy and the log percentage native woody vegetation at one scale and one temporal scale.-Again for simplicity, we describe our statistical model for landscape-scale bird occupancy $(\operatorname{logit}(\mathrm{p}))$. Our response variable, the predicted probability of occupancy $(p)$, then varied at three scales; between-landscape, between-year, and betweenyear within-landscape. The same applied to the candidate explanatory variables representing the amount of habitat (primarily here the log of percentage vegetation cover).

Importantly, observations within the same landscape shared common spatial factors, and this may make the results more homogeneous than those of a random sample of observations drawn across landscapes. Our proposed statistical model reflected this feature, and hence we specified and accounted for the spatial dependence structure by treating the factor "Landscape" as a random effect in our model. 
If we regard Landscape $(l)$ and Year $(y)$ as random effects and vegetation cover as a fixed effect, we have

$$
Y_{i j}=\mu+l_{i}+y_{j}+\beta X_{i j}+\varepsilon_{i j}
$$

where $\mu=$ grand mean; $\beta=$ the regression coefficient for the explanatory variable $X_{i j}$, the log vegetation cover. Assume $l_{i}, i=1, \cdots, 23$, independent $N\left(0, \sigma_{l}^{2}\right), y_{j}, j=1,2$ independent $N\left(0, \sigma_{y}^{2}\right)$, and $\varepsilon_{i j}$ independent $N\left(0, \sigma_{\varepsilon}^{2}\right)$, where $\sigma_{l}^{2}, \sigma_{y}^{2}, \sigma_{\varepsilon}^{2}$ are known as variance components. The parameter $Y_{i j}$ denotes logit $\left(p_{i j}\right)$ on the $i$ th landscape in the $j$ th year.

The above model fits within the general framework of general linear mixed models (Galwey 2006). Restricted maximum likelihood was used to estimate variance components and weighted least squares for estimating fixed effects. We assessed statistical significance of effects by calculating adjusted Wald statistics (Kenward and Rogers 1997). Extrinsic weights were based on the standard errors of the predicted values obtained from the previous analysis. We routinely used general model checking procedures to identify aberrant data and check the model assumptions.

We emphasize that a special feature of longitudinal data is that inferences pertaining to regression relationships at different levels can be segregated. For example, the within-landscape regression coefficient can be estimated by comparing individual responses at two times (2002 and 2010) assuming the given habitat variable changes with time. This eliminates the effect of unmeasured geographic and environmental characteristics, which vary across the target population, and which may obscure the estimation of direct betweenlandscape relationships; that is, their influence is cancelled in the estimation of the within-landscape relationships.

\section{RESUlTS}

\section{Cross-sectional relationships between bird occupancy and the amount of native vegetation cover}

We found that the slopes of the cross-sectional relationships between the occupancy of bird species and amount of vegetation cover were generally consistent at the landscape and farm scale, but levels of statistical significance were seldom the same at all scales (Figs. 4 and 5; Appendix B). For example, the Superb Parrot and Pied Butcherbird (Cracticus nigrogularis) were most often found in landscapes and farms with low levels of native vegetation cover $(P<0.05)$ (Figs. 4a and 5; Appendix B). However, there was no evidence of a relationship at the site level for these species. The Noisy Miner was significantly more likely to be recorded in landscapes with low levels of native vegetation cover $(P$ $=0.001)$, but exhibited no significant native vegetation cover relationships at the farm and site scale (Fig. 4b; Appendix B).

We found significant scale-invariant negative relationships between bird occupancy and native vegetation cover for the Galah (Eolophus roseicapillus) (Fig. 4c) and Brown Songlark (Fig. 4d). Other significant negative responses included those for the Common Starling at the farm and site scale (consistent slope at the landscape scale) and the Red-rumped Parrot (Psephotus haematonotus) at the site scale (Appendix B).

Significant positive responses between species occupancy and native vegetation cover included those for the White-plumed Honeyeater (Lichenostomus penicillatus) at the landscape and farm scale (Fig. 4e; Appendix B); the Grey Shrike-thrush (Colluricincla harmonica) at the landscape and site scale; Crimson Rosella (Platycercus elegans), Magpie-lark (Grallina cyanoleuca), Red Wattlebird (Anthochaera carunculata), and the Willie Wagtail (Rhipidura leucophrys; see Plate 1) at the landscape scale; and the Rufous Whistler at the site scale (Fig. 4f; Appendix B).

\section{Temporal relationships between bird occupancy and the amount of native vegetation cover}

There was a $3.5 \%$ increase in the amount of native vegetation cover in our study area between 2002 and 2010. We found a significant negative relationship between temporal change in vegetation cover and temporal change in occupancy of the Jacky Winter at the landscape scale $(P=0.04)$ (Appendix $C)$. There was, however, evidence of significant negative relationships between occupancy of several other species at the farm scale, site scale, or both, and the increase in vegetation cover (Fig. 5; Appendix C). This included the Magpie Lark and Noisy Miner at both the farm and site scale, the Grey Fantail (Rhipidura albiscapa) and Willie Wagtail at the farm scale, and Crested Shrike-tit (Falcunculus frontatus) at the site scale. In contrast, we found a positive relationship between temporal increases in vegetation cover and changes in occupancy of Superb Parrot at both the farm and site scale, and the Rufous Whistler at the site scale (Fig. 5; Appendix C).

\section{Comparison of cross-sectional vs. temporal relationships between bird occupancy and amount of native vegetation cover}

Several species exhibited marked differences between cross-sectional responses to the amount of native vegetation cover compared to the response to temporal changes in vegetation cover (Figs. 5 and 6). There was weak evidence $(P=0.089)$ that the Willie Wagtail was more likely to be found on farms with more vegetation cover, but it responded negatively $(P=0.047)$ to the temporal increase in cover at the farm scale (Fig. 6a). The Superb Parrot was less likely to be recorded on farms with high levels of native vegetation $(P=0.018)$, but exhibited a significant $(P=0.003)$ positive response to a temporal increase in vegetation cover at the farm scale (Fig. 6b). The Noisy Miner showed no significant relationships with the amount of cover at the farm and site scales, but was significantly less likely to be recorded on farms $(P=0.004$; Fig. $6 \mathrm{c})$ and on sites where there 

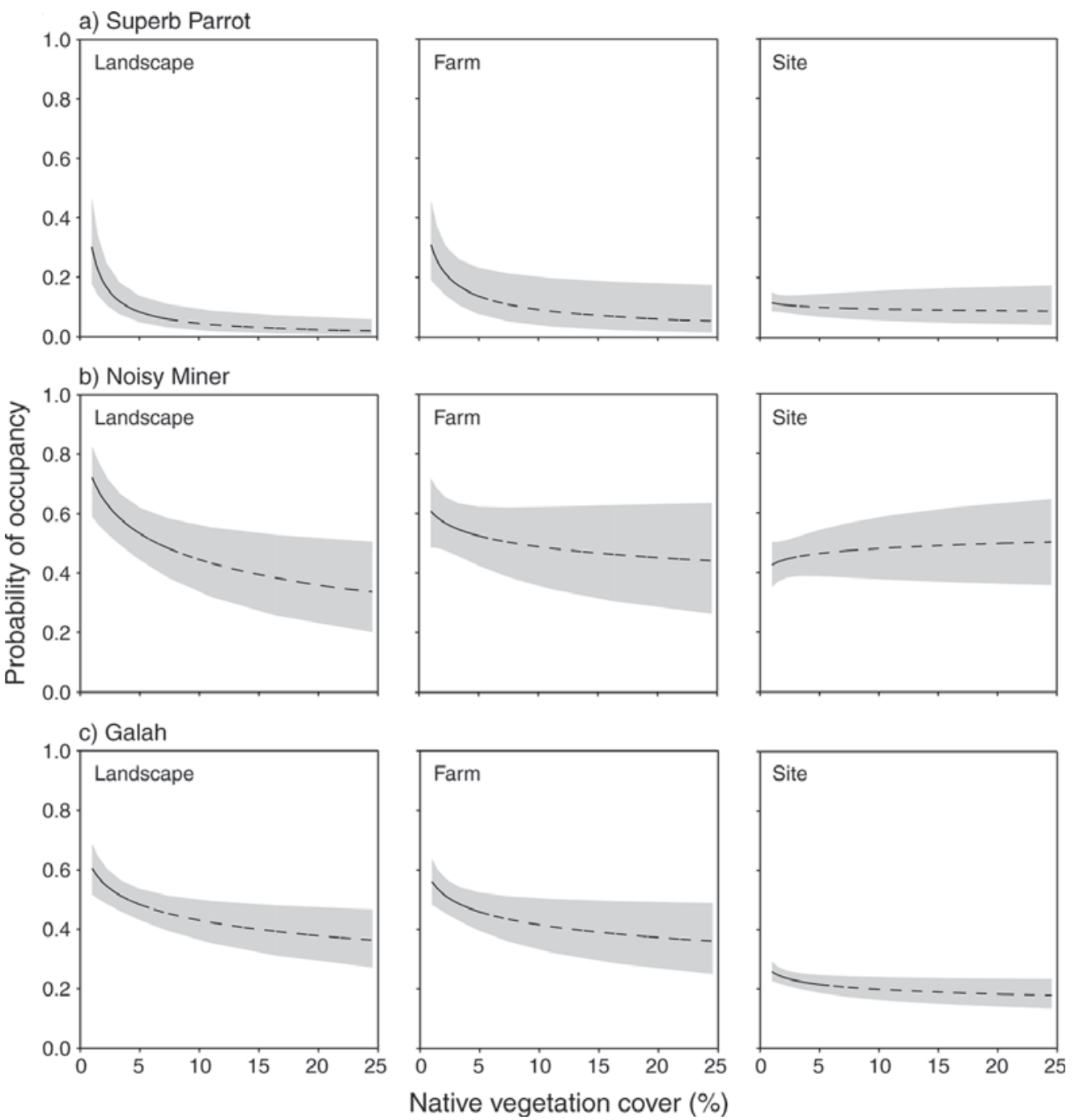

FIG. 4. Cross-sectional relationships between bird occupancy and vegetation cover at the landscape, farm, and site scales for selected species. (a) Superb Parrot; (b) Noisy Miner; (c) Galah; (d) Brown Songlark; (e) White-plumed Honeyeater; (f) Rufous Whistler. All scientific names of birds can be found in Appendix A.

was a temporal increase in cover $(P<0.001$; data not shown). We found a similar response in the Whiteplumed Honeyeater, which showed no response to the amount of native vegetation cover, but a highly significant $(P<0.001)$ negative response to temporal changes in vegetation cover (Fig. 6d). The Grey Shrikethrush was significantly more likely $(P=0.001)$ to be found on sites with more cover but exhibited no response to temporal increases in cover at a given site (Fig. 6e). We also found that the Rufous Whistler was more likely $(P=0.017)$ to occupy sites with more vegetation cover and also responded positively $(P=$ $0.006)$ to increases in vegetation cover at a given site (Fig. 6f).

\section{Discussion}

We have statistically examined spatial-scale effects on both cross-sectional and temporal relationships between bird occupancy and native vegetation cover. Our analyses lead to two important general principles, namely: (1) the empirical response of a given species to native vegetation cover at a given spatial scale may be quite different from its response at another scale, and (2) there can be notable differences between cross-sectional responses and temporal response and these differences will be scale-sensitive for some species but scaleinvariant for others. Our work has significant implications for both the spatial scale of conservation efforts in agricultural environments, and the response of biota to strategies to maintain existing vegetation cover vs. efforts to increase the amount of cover over time.

\section{Cross-sectional relationships between bird occupancy} and the amount of native vegetation cover

The effects of spatial scale on relationships between vegetation cover and biodiversity have rarely been 

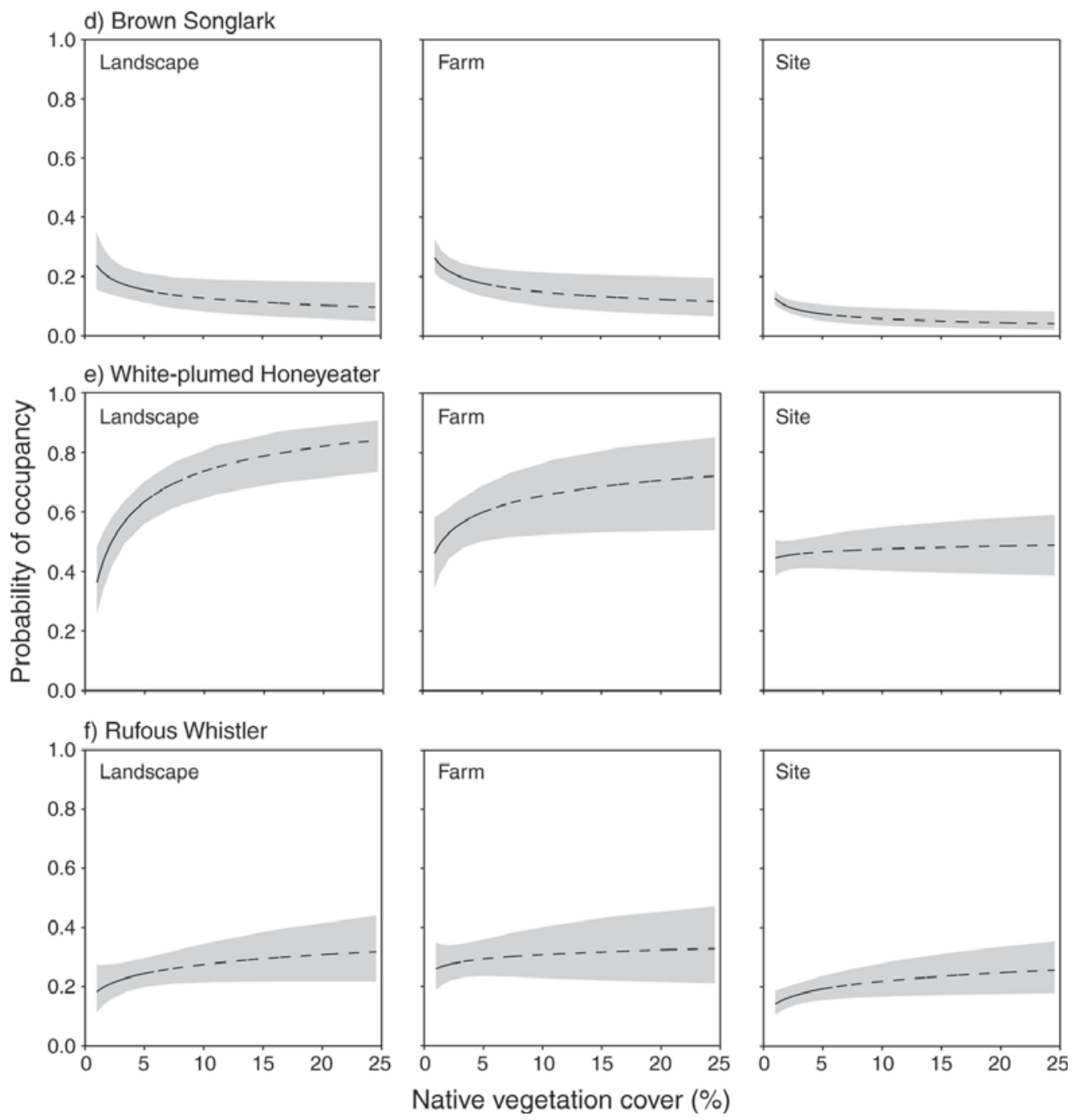

FIg. 4. Continued.

examined in agricultural environments (Tscharntke et al. 2012). Indeed, to the best of our collective knowledge, the work reported here is the first time that spatial scale effects have been quantified for individual bird species in Australian woodland ecosystems. We found relationships with vegetation cover for several bird species, including both scale-invariant and scalesensitive responses. Our findings support those of previous workers that suggest that different species will respond to factors at different spatial scales (e.g., Wiens et al. 1987, Holling 1992, Levin 1992, Saab 1999), including the amount of native vegetation cover, and that the same species can exhibit different responses at different spatial scales (Forman 1964, Diamond 1973, Mackey and Lindenmayer 2001).

Spatial scale effects for particular species can often be explained by aspects of their ecology. In this study, the Superb Parrot is a wide-ranging granivore that forages extensively in croplands that dominate heavily cleared landscapes and farms (Manning and Lindenmayer
2009). This would account for negative relationships between the occupancy by the Superb Parrot and the amount of native vegetation cover at a landscape scale (see Appendix B). However, the Superb Parrot nests in large, old trees (Manning and Lindenmayer 2009) and this may explain the positive relationship with vegetation cover at the site level.

The amount of native vegetation cover is likely to act as a crude surrogate for the amount of potential habitat for woodland-dependent birds, some of which are species of conservation concern, and that showed positive relationships with the amount of native vegetation (see Appendix B). Several processes are likely to underpin positive relationships between vegetation cover and occupancy for many species. These include local immigration and extinction rates (Hanski 1994), habitat diversity and random placement, all of which are likely to lead to greater occupancy of a larger patch than a smaller patch by a given species (Connor and McCoy 1979). In addition, larger patches may be less disturbed 

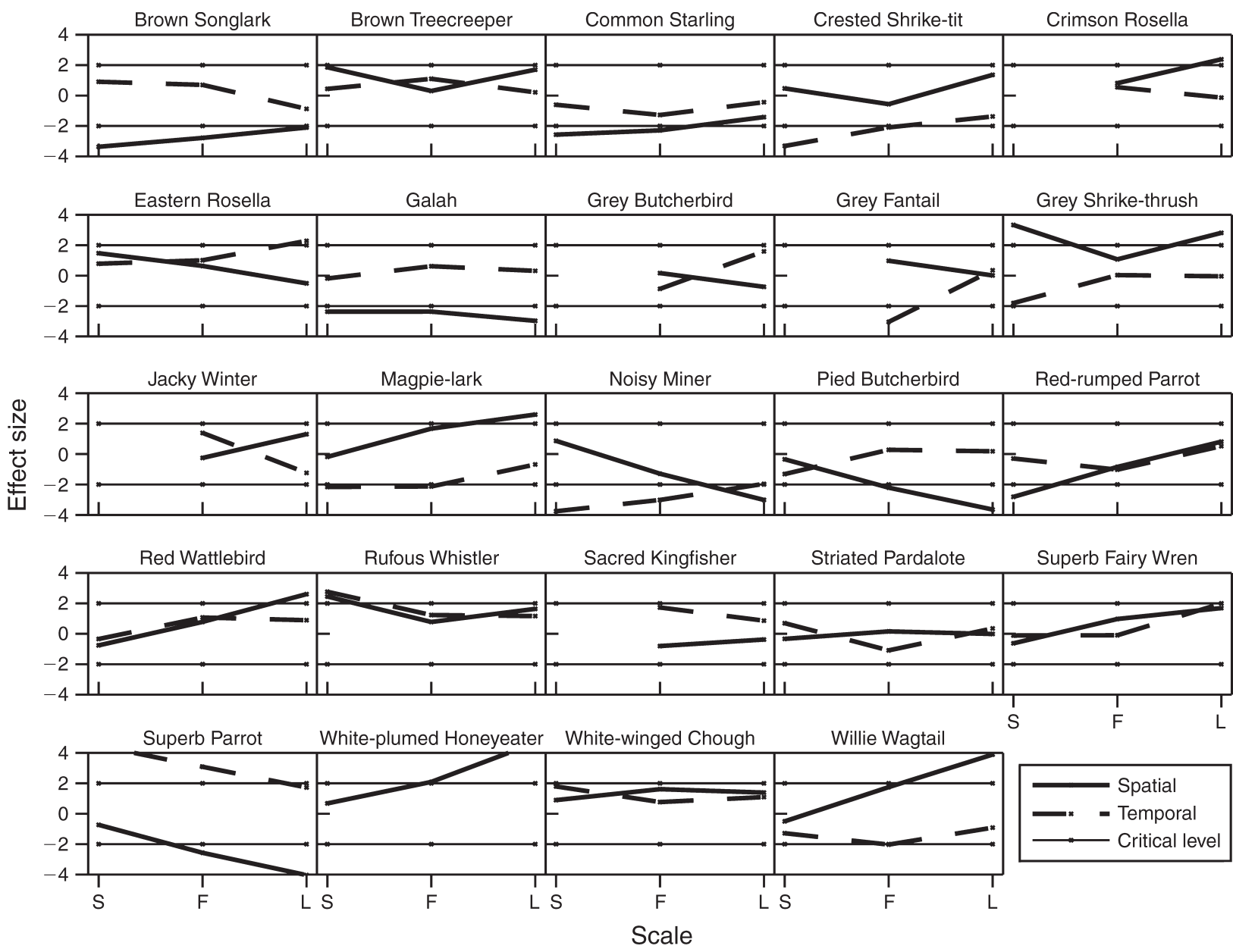

FIG. 5. Trellis plot, showing for each selected bird species: (1) a plot of effect sizes of the cross-sectional relationship between the odds of occupancy and $\log (\%$ cover of native vegetation) at three scales: landscape (L), farm (F), and site (S); (2) a plot of effect sizes of the relationship between the change (between 2002 and 2010) in odds of occupancy and change in $\log (\%$ cover of native vegetation) at the three scales: landscape (L), farm (F), and site (S). A solid line joins effects for (1), and a dashed line joins effects for (2). All scientific names of birds can be found in Appendix A.

and support more vegetation in better condition (e.g., from edge effects [Ries et al. 2004]), and therefore may support more suitable habitat for a given species (Knight and Fox 2000).

\section{Temporal relationships between bird occupancy and the amount of native vegetation cover}

The majority of studies of biodiversity worldwide are cross-sectional investigations, with longitudinal studies being relatively uncommon (Likens 1989, Muller et al. 2011). Even fewer studies have quantified temporal changes in biota alongside temporal changes in vegetation cover at different spatial scales. We found evidence of positive relationships between changes in bird occupancy and temporal changes in vegetation cover for some species, but often at different spatial scales (Appendix B). Several bird species displayed contrasting responses to the temporal change in vegetation cover. This is because increases in vegetation cover over time are a result of both the expansion of areas of natural regrowth, such as in gullies or the edges of remnants, as well as the addition of new restoration plantings (Geddes et al. 2011). Previous work has indicated that these areas provide suitable habitat for some species (e.g., the Rufous Whistler), but are avoided by others (e.g., Noisy Miner) (Cunningham et al. 2008, Lindenmayer et al. 2010b). Our study suggests that conservation and restoration interventions to increase habitat amount might therefore affect species differently depending on their preference for young vegetation.

\section{Comparison of cross-sectional vs. temporal relationship} between bird occupancy and amount of native vegetation cover

To the best of our collective knowledge, our study is the first to contrast differences in bird responses to existing (cross-sectional) levels of vegetation cover with their response to temporal changes in the amount of cover. Indeed, for some species the responses were not consistent (Fig. 6d; e.g., the Superb Parrot). We suggest 

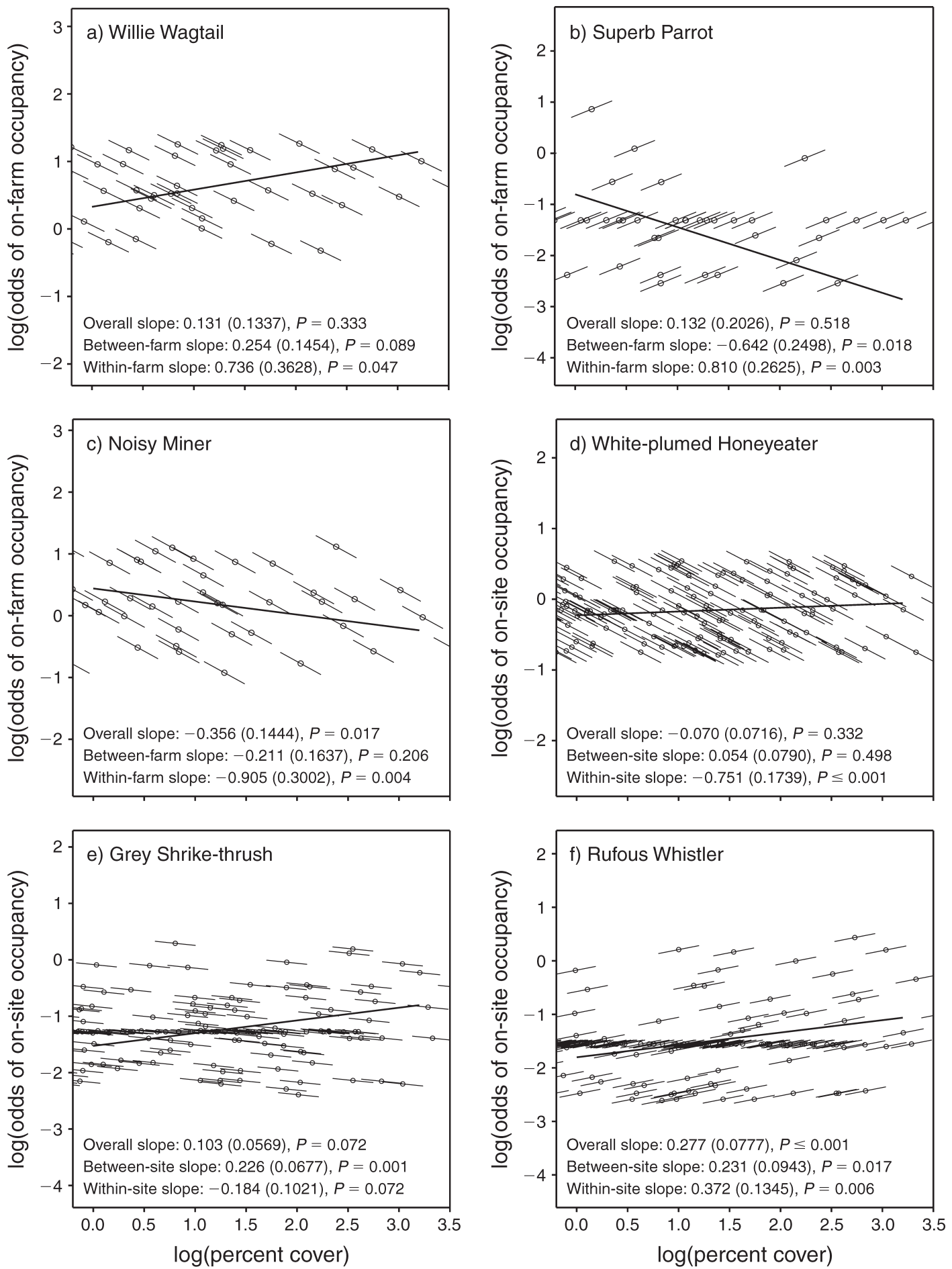

FIG. 6. Regression relationships of the odds of occupancy of a given bird species between and within spatial units. Units refers to a particular scale (farm or site). Units are arranged along the $x$-axis according to the logarithm of percentage cover of native vegetation. The thick black line represents the "between-unit slope" and the short lines through unit means represent the mean within-unit slope. As an example, the "between-farm" slope for the Willie Wagtail is $0.25 \pm 0.14$ (mean \pm SE) which indicates that for every increase of 1 unit in log vegetation cover there is $\sim 25 \%$ increase in the odds of occupancy. The "within-farm slope" is shown by the short line through each dot. This represents the mean rate of change in bird occupancy with the change in log vegetation cover on farms between 2002 and 2010. In the case of the Willie Wagtail, the slope is negative, showing decrease of 0.74 \pm 0.36 in the odds of occupancy at any given farm with a change in the log vegetation cover of 1 unit. The within-farm slope represents the direct relationship between change in bird occupancy and change in vegetation cover at a given farm. A weighted combination of the within-farm and between-farm slopes gives the overall slope. All scientific names of birds can be found in Appendix A. 
this finding is associated with broad differences between existing vegetation cover and changes in vegetation over time. Most of the past and existing vegetation on farms or in landscapes is old-growth temperate woodland. In contrast, new areas of vegetation added to sites, farms and landscapes during our study were typically stands of natural regrowth or replantings (Cunningham et al. 2007). Previous studies have clearly shown that these different kinds of vegetation act as markedly different habitats for different bird species (Lindenmayer et al. 2012). In the case of the Noisy Miner, the species is less likely to be recorded in landscapes with low levels of cover, which are typically dominated by woodland composed of scattered paddock trees and where birds have ready line of sight to maintain group cohesion and detect predators and competitors. However, the Noisy Miner was negatively associated with temporal increases in cover at the farm and site levels, where it is likely that it avoids dense vegetation like plantings and regrowth, possibly because such kinds of vegetation disrupt its hyper-aggressive colonial behavior toward other birds. In another example, we showed that the Crested Shriketit tends to select landscapes with high existing levels of cover (Appendix B), but responds negatively to temporal change in cover at all scales (Appendix $C$ ). This can be explained by this species' strong association with large trees with hanging bark, which are not provided by young trees and plantings (Vesk et al. 2008).

Our findings underscore how longitudinal studies can lead to new insights not provided by cross-sectional data (see also Wiens 1981, Lovett et al. 2007). This leads to the identification of ecological responses to temporal change that would not be possible in short-term studies or cross-sectional studies (Kruuk and Hill 2008). One caveat to our findings, however, is that our data generally showed stronger cross-sectional effects than temporal effects at larger scales. Given high levels of inherent variability, detecting temporal relationships will be difficult for comparatively small samples for a relatively short period of time. We therefore encourage researchers to strongly promote the establishment and ongoing maintenance of long-term studies.

\section{Management implications}

The new insights reported here have conservation implications for agricultural landscapes, including areas where large investments are made in an effort to conserve biodiversity (such as through agri-environment schemes; see Kleijn et al. 2011). These insights are important because a substantial problem for biodiversity conservation in agricultural landscapes has been the loss of native vegetation cover for cultivation and the establishment of pastures for livestock grazing (Tscharntke et al. 2012). Conversely, there are many landscapes around the world where native vegetation cover has been increasing, either as a result of land abandonment (Scherr and McNeely 2008), deliberate replanting of native vegetation (Benayas et al. 2009), or both (Lunt et al. 2010). Indeed, increasing the amount of native vegetation cover (through deliberate planting or promoting natural regeneration) is one of the major forms of management intervention that can be employed to improve conservation outcomes in agricultural landscapes (Lindenmayer et al. 2012). Yet biodiversity responses to such positive temporal changes in increased levels of vegetation cover in agricultural landscapes are rarely quantified.

Our work has demonstrated that both the spatial scales of existing vegetation cover, and changes in vegetation cover over time, matter for different bird species. As an example, we found scale-invariant species (e.g., the Brown Treecreeper) responded positively (although not significantly) to existing vegetation cover at all scales. The Brown Treecreeper also responded positively to temporal increases in cover at the farm and site scale (Appendix C). Therefore, both maintaining existing cover and interventions to establish new vegetation will have a positive effect on this particular species of conservation concern at all scales and over time. In contrast, site-based restoration programs in otherwise heavily cleared landscapes will have a positive effect on the threatened Superb Parrot, as indicated by its negative association with vegetation cover at the landscape scale but positive response to temporal increases in cover at the site level. Some species of conservation concern (e.g., Jacky Winter) were positively associated with existing overall levels of vegetation cover but responded negatively to temporal increases in native vegetation cover (Fig. 5). Strategies to conserve such kinds of species must be focused on preventing vegetation removal. This is because simply adding vegetation back into a landscape or on a farm following previous clearing (e.g., through replanting programs) will not directly restore such species. This, in turn, has major implications for the effectiveness of biodiversity conservation approaches like offsetting (Maron et al. 2012b), as it suggests that clearing of oldgrowth woodland vegetation on a farm or in a landscape may not be readily substituted for by the establishment elsewhere of new areas of vegetation (plantings and natural regeneration).

A key research challenge is to develop an improved understanding of the ecological scales of responses of biodiversity to both the total amount of vegetation cover in agricultural landscapes and temporal changes in the amount of cover (Tscharntke et al. 2012). This is critical for guiding both the protection (e.g., reservation) of existing areas of native vegetation in agricultural areas and identifying the most effective programs (such as those through agri-environment schemes) for increasing the amount of native vegetation. We have demonstrated there are inter-specific, scale-dependent differences in responses to existing vegetation cover and temporal changes in vegetation cover. This underscores the importance of clearly articulating the 
objectives of conservation efforts at different scales and over time, including identifying those taxa being targeted in vegetation preservation and replanting programs (Perkins et al. 2011). By taking a multiscaled approach, we have been able to better identify which species are responding to the amount of vegetation cover as well as the changes in vegetation cover over time.

\section{ACKNOWLEDGMENTS}

We thank the Australian Research Council, the Murray Catchment Management Authority, and the Caring for Our Country Program for funding for this project. The work reported in this paper was a direct result of questions posed by David Lesslie, Emmo Willinck, Jack Chubb, and David Costello. Claire Shepherd assisted in many key aspects of manuscript preparation.

\section{Literature Cited}

Allen, T. F. H., and T. W. Hoekstra. 1992. Toward a unified ecology. Columbia University Press, New York, New York, USA.

Andren, H. 1994. Effects of habitat fragmentation on birds and mammals in landscapes with different proportions of suitable habitat: a review. Oikos 71:355-366.

Askins, R. A., M. J. Philbrick, and D. S. Sugeno. 1987. Relationships between the regional abundance of forest and the composition of bird communities. Biological Conservation 39:129-152.

Benayas, J. M. R., A. C. Newton, A. Diaz, and J. M. Bullock. 2009. Enhancement of biodiversity and ecosystem services by ecological restoration: a meta-analysis. Science 325:11121124.

Betts, M. G., J. C. Hagar, J. W. Rivers, J. D. Alexander, K. McGarical, and B. C. McComb. 2010. Thresholds in forest bird occurrence as a function of the amount of early-seral broadleaf forest at landscape scales. Ecological Applications 20:2116-2130.

Carigan, V., and M.-A. Villard. 2002. Selecting indicator species to monitor ecological integrity: a review. Environmental Monitoring and Assessment 78:45-61.

Chave, J. 2013. The problem of pattern and scale in ecology: what have we learned in 20 years? Ecology Letters 16 Issue Supplement s1:4-16.

Clarke, M. F., and M. J. Grey. 2010. Managing an overabundant native bird: the Noisy Miner (Manorina melanocephala). Pages 115-125 in D. B. Lindenmayer, A. F. Bennett, and R. J. Hobbs, editors. Temperate woodland conservation and management. CSIRO Publishing, Melbourne, Australia.

Connor, E. F., and E. D. McCoy. 1979. The statistics and biology of the species-area relationship. American Naturalist 113:791-833.

Cunningham, R. B., D. B. Lindenmayer, M. Crane, D. Michael, and C. MacGregor. 2007. Reptile and arboreal marsupial response to replanted vegetation in agricultural landscapes. Ecological Applications 17:609-619.

Cunningham, R. B., D. B. Lindenmayer, M. Crane, D. R. Michael, C. MacGregor, R. Montague-Drake, and J. Fischer. 2008. The combined effects of remnant vegetation and tree planting on farmland birds. Conservation Biology $22: 742-752$

Date, E. M., H. F. Recher, H. A. Ford, and D. A. Stewart. 1996. The conservation and ecology of rainforest pigeons in northern New South Wales. Pacific Conservation Biology 2:299-308.

Diamond, J. M. 1973. Distributional ecology of New Guinea birds: Recent ecological and biogeographical theories can be tested on the bird communities of New Guinea. Science 179:759-769.

Diggle, P. J., L. Kung-Yee, and S. L. Zeger. 1996. Analysis of longitudinal data. Oxford University Press, Oxford, UK.

Ford, H. A. 2011. The causes of decline of birds of eucalypt woodlands: advances in our knowledge over the last 10 years. Emu 111:1-9.

Forman, R. T. T. 1964. Growth under controlled conditions to explain the hierarchical distributions of a moss, Tetraphis pellucida. Ecological Monographs 34:1-25.

Furby, S. 2002. Land cover change: specifications for remote sensing analysis. Australian Greenhouse Office, Canberra, Australia.

Galwey, N. W. 2006. Introduction to mixed modelling: beyond regression and analysis of variance. John Wiley, London, UK.

Geddes, L. S., I. D. Lunt, L. Smallbone, and J. W. Morgan. 2011. Old field colonization by native trees and shrubs following land use change: could this be Victoria's largest example of landscape recovery? Ecological Management and Restoration 12:31-36.

Guerra, P. A., and S. M. Reppert. 2013. Coldness triggers northward flight in remigrant Monarch butterflies. Current Biology 23:419-423.

Hall, L. S., P. A. Krausman, and M. L. Morrison. 1997. The habitat concept and a plea for the use of standard terminology. Wildlife Society Bulletin 25:173-182.

Hanski, I. 1994. Patch occupancy dynamics in fragmented landscapes. Trends in Ecology and Evolution 9:131-135.

Hanski, I. 1999. Metapopulation ecology. Oxford University Press, Oxford, UK.

Holling, C. S. 1992. Cross-scale morphology, geometry, and dynamics of ecosystems. Ecological Monographs 62:447-502.

Homan, R. N., B. S. Windmiller, and J. M. Reed. 2004. Critical thresholds associated with habitat loss for two vernal poolbreeding amphibians. Ecological Applications 14:1547-1553.

Keith, D. A. 2004. Ocean shores to desert dunes. The native vegetation of New South Wales and the ACT. NSW Department of Environment and Conservation, Sydney, Australia.

Kenward, M. G., and J. H. Rogers. 1997. Small sample inference for fixed effects from restricted maximum likelihood. Biometrics 53:983-997.

Kleijn, D., M. Rundlof, J. Scheper, H. G. Smith, and T. Tscharntke. 2011. Does conservation on farmland contribute to halting biodiversity decline? Trends in Ecology and Evolution 26:474-481

Knight, E. H., and B. J. Fox. 2000. Does habitat structure mediate the effects of forest fragmentation and humaninduced disturbance on the abundance of Antechinus stuartii? Australian Journal of Zoology 48:577-595.

Koenig, W. D. 1998. Spatial autocorrelation in California land birds. Conservation Biology 12:612-620.

Kruuk, L., and W. G. Hill. 2008. Evolutionary dynamics of wild populations: the use of long-term pedigree data. Proceedings of the Royal Society B 275:593-596.

Levin, S. A. 1992. The problem of scale and pattern in ecology: The Robert H. Macarthur Award lecture. Ecology 73:19431967.

Likens, G. E., editor. 1989. Long-term studies in ecology: approaches and alternatives. Springer-Verlag, New York, New York, USA.

Lindenmayer, D. B., A. F. Bennett, and R. J. Hobbs, editors. 2010a. Temperate woodland conservation and management. CSIRO Publishing, Melbourne, Australia.

Lindenmayer, D. B., and R. B. Cunningham. 2011. Longitudinal patterns in bird reporting rates in a threatened ecosystem: Is change regionally consistent? Biological Conservation 144:430-440.

Lindenmayer, D. B., E. J. Knight, M. J. Crane, R. MontagueDrake, D. R. Michael, and C. I. MacGregor. 2010b. What 
makes an effective restoration planting for woodland birds? Biological Conservation 143:289-301.

Lindenmayer, D. B., A. R. Northrop-Mackie, R. MontagueDrake, D. Michael, M. Crane, S. Okada, C. MacGregor, and P. Gibbons. 2012. Not all kinds of regrowth are created equal. Regrowth type influences bird assemblages in threatened Australian woodland ecosystems. PLOS One 7:e34527.

Lovett, G. M., D. A. Burns, C. T. Driscoll, J. C. Jemkins, M. J. Mitchell, L. Rustad, J. B. Shanley, G. E. Likens, and R. Haeuber. 2007. Who needs environmental monitoring? Frontiers in Ecology and the Environment 5:253-260.

Lunt, I. D., L. M. Winsemius, S. P. McDonald, J. W. Morgan, and R. L. Dehaan. 2010. How widespread is woody plant encroachment in temperate Australia? Changes in lowland woodland and coastal ecosystems in Victoria from 1989 to 2005. Journal of Biogeography 37:722-732.

Mackey, B. G., and D. B. Lindenmayer. 2001. Towards a hierarchical framework for modelling the spatial distribution of animals. Journal of Biogeography 28:1147-1166.

Manning, A. D., and D. B. Lindenmayer. 2009. Paddock trees, parrots and agricultural production: An urgent need for large-scale, long-term restoration in south-eastern Australia. Ecological Management and Restoration 10:126-135.

Maron, M., M. Bowen, R. A. Fuller, G. C. Smith, T. J. Eyre, M. Mathieson, J. E. Watson, and C. A. McAlpine. $2012 a$. Spurious thresholds in the relationship between species richness and vegetation cover. Global Ecology and Biogeography 21:682-692.

Maron, M., R. J. Hobbs, A. Moilanen, J. W. Matthews, K. Christie, T. A. Gardner, D. A. Keith, D. B. Lindenmayer, and C. A. McAlpine. 2012b. Faustian bargains? Restoration realities in the context of biodiversity offset policies. Biological Conservation 155:141-148.

Montague-Drake, R. M., D. B. Lindenmayer, and R. B. Cunningham. 2009. Factors affecting site occupancy by woodland bird species of conservation concern. Biological Conservation 142:2896-2903.

Muller, F., C. Baessler, H. Schubert, and S. Klotz, editors. 2011. Long-term ecological research. Between theory and application. Springer, Dordrecht, The Netherlands.

Munro, N., and D. B. Lindenmayer. 2011. Planting for wildlife: a practical guide to restoring native woodlands. CSIRO Publishing, Melbourne, Australia.

Perkins, A. J., H. E. Maggs, A. Watson, and J. D. Wilson. 2011. Adaptive management and targeting of agri-environment schemes does benefit biodiversity: a case study of the corn bunting Emberiza calandra. Journal of Applied Ecology 48:514-522.
Pyke, G. H., and H. F. Recher. 1983. Censusing Australian birds: a summary of procedures and a scheme for standardisation of data presentation and storage. Pages 55-63 in S. J. Davies, editor. Methods of censusing birds in Australia. Proceedings of a Symposium Organised by the Zoology section of the ANZAAS and the Western Australian Group of the Royal Australasian Ornithologists Union. Department of Conservation and Environment, Perth, Australia.

Radford, J. Q., A. F. Bennett, and G. J. Cheers. 2005. Landscape-level thresholds of habitat cover for woodlanddependent birds. Biological Conservation 124:317-337.

Reid, J. 1999. Threatened and declining birds in the New South Wales sheep-wheat belt. I. Diagnosis, characteristics and management. Unpublished report to NSW National Parks and Wildlife Service. CSIRO Wildlife and Ecology, Canberra, Australia.

Ries, L., R. J. Fletcher, J. Battin, and T. D. Sisk. 2004 Ecological responses to habitat edges: Mechanisms, models, and variability explained. Annual Review of Ecology, Evolution, and Systematics 35:491-522.

Saab, V. 1999. Importance of spatial scale to habitat use by breeding birds in riparian forests: a hierarchical analysis. Ecological Applications 9:135-151.

Scherr, S. J., and J. A. McNeely. 2008. Biodiversity conservation and agricultural sustainability: towards a new paradigm of "ecoagriculture" landscapes. Philosophical Transactions of the Royal Society B 263:477-494.

Schneider, D. C. 1994. Quantitative ecology. Temporal and spatial scaling. Academic Press, San Diego, California, USA.

Storch, D., P. Keil, and W. Jetz. 2012. Universal species-area and endemics-area elationships at continental scales. Nature 488:78-81.

Swift, T. L., and S. J. Hannon. 2010. Critical thresholds associated with habitat loss: a review of the concepts, evidence and applications. Biological Reviews 85:35-53.

Tscharntke, T., et al. 2012. Landscape moderation of biodiversity patterns and processes - eight hypotheses. Biological Reviews 87:661-685.

Vesk, P., R. Nolan, J. W. Thomson, J. W. Dorrough, and R. Mac Nally. 2008. Time lags in the provision of habitat resources through revegetation. Biological Conservation 141:174-186.

Wiens, J. A. 1981. Single-sample surveys of communities: are the revealed patterns real? American Naturalist 117:90-98.

Wiens, J. A., J. T. Rotenberry, and B. Van Horne. 1987. Habitat occupancy patterns of North American shrubsteppe birds: the effects of spatial scale. Oikos 48:132-147.

\section{Supplemental Material}

\section{Appendix A}

Bird species recorded in surveys conducted between 2002 and 2010 in the South West Slopes of New South Wales, southeastern Australia (Ecological Archives A024-076-A1).

\section{Appendix B}

Slope parameters and associated statistics of relationships between the odds of occupancy of individual bird species and the log of the percentage of native vegetation cover at the landscape, farm, and site scale (Ecological Archives A024-076-A2).

\section{Appendix C}

Slope parameters and associated statistics of relationships between the temporal change in odds of occupancy of individual bird species and temporal changes in the log of percent native vegetation cover at the landscape, farm, and site scale (Ecological Archives A024-076-A3). 